\title{
Barriers to effective pharmacy practice in low- and middle-income countries
}

This article was published in the following Dove Press journal:

Integrated Pharmacy Research and Practice

17 March 2014

Number of times this article has been viewed

\author{
Zaheer-Ud-Din Babar' \\ Shane Scahill ${ }^{2}$ \\ 'School of Pharmacy, Faculty of \\ Medical and Health Sciences, \\ University of Auckland; ${ }^{2}$ School of \\ Management, College of Business, \\ Massey University, Auckland, \\ New Zealand
}

Correspondence: Zaheer-Ud-Din Babar School of Pharmacy, Faculty of Medical and Health Sciences, University of Auckland, Private Mail Bag 92019, Auckland, New Zealand

Tel +6493737599 ext 88436

Fax +649367 7192

Email z.babar@auckland.ac.nz

\begin{abstract}
The role of the pharmacist within health care systems is undergoing significant development with the continual introduction of new medicine entities, the emergence of new resistant microbes, and changes in the delivery of health services. In developed countries, pharmacists are playing a key role in promoting safe and effective use of medicines; however, in the majority of low- and middle-income countries, they still have to reach their true potential. This article set out to explore the barriers to effective practice in low- and middle-income countries, and concluded that a) health systems; b) level and quality of services provided by community pharmacies; and c) educational and professional factors are the three main barriers.
\end{abstract}

Keywords: low- and middle-income countries, pharmacy education, pharmacy practice, barriers

\section{Introduction}

The role of the pharmacist within health care systems is undergoing significant development with the continual introduction of new medicine entities, the emergence of new resistant microbes, and changes in the delivery of health services within the overall system. With increasing health care costs, the pharmacists' role in ensuring the procurement and quality use of cost-effective medicines is vital. Globally, pharmacists are the third largest health care professional group. ${ }^{1}$ However, the profession still has a long way to go in order to contribute significantly in the health care systems of low- and middle-income countries. ${ }^{2}$

The aim of effective pharmacy practice, including clinical pharmacy, is to promote the safe and quality use of medicines. However, improvement in medicine use is very much dependent on the health systems within which care is delivered. ${ }^{3}$ Health system development has benefited from advances in science, technology, innovation, and wide-ranging policy measures which support public health. Developed economies have been at the forefront of innovation and the quality of service provision within the pharmacy industry has contributed significantly to patient outcomes in these countries. ${ }^{3}$ However, the situation in developing economies seems different. On the other hand, there has been some dialogue around the potential for improvement in pharmacy practice at a global level. However, it is not possible to apply a single change model to pharmacy service provision worldwide, as the system within which the pharmacy service is embedded (the environment), will have significant bearing on the practices that take place. In this way, context is very important, and understanding the key differences between health systems and how the industry is positioned within low- and middle-income countries relative to their high-income counterparts is fundamental 
to grappling with the barriers that need to be overcome. ${ }^{4}$ The International Pharmaceutical Federation (FIP) has made a point of highlighting the gap between pharmacy service models and provision in developed and developing countries and the need for this to be urgently addressed. ${ }^{4}$

According to the FIP, the demand placed on limited resources (both human and financial), within their member states is growing. ${ }^{4}$ This paper aligns with the FIP call to order and outlines in some detail three major barriers to effective pharmacy practice in low- and middle-income countries, including: the health systems themselves, the levels of services provided by pharmacists, and education and professional factors.

\section{Health systems}

There is widespread evidence of failure to implement interventions that have been shown to be cost-effective by high-quality research. ${ }^{5-7}$ Studies in both the US and Europe have shown that around $30 \%-50 \%$ of patients fail to receive clinical interventions that are justified according to the best scientific evidence. ${ }^{8,9}$ Low-income countries face additional challenges to using research evidence, including: the underdevelopment of their health systems, the lack of professional regulation, and a lack of access to evidence. One example in pharmacy is the lack of availability of essential medicines. Without this access, it makes it very difficult for pharmacists to deliver even the most basic evidence-based health care and effective pharmacy practice.

Other factors include the cost of medicines, storage of medicines, distribution channels, accessibility, the lack of universal health coverage, no remuneration for pharmacists to provide services, and the lack of recognition of the role of the pharmacist within the wider health care system. ${ }^{4}$

\section{Level and quality of services provided by community pharmacies}

In many countries, community-based private pharmacy businesses are a key resource for both health advice and provision of medicines. ${ }^{10}$ However, the quality of the service provided is unclear and has been questioned. Smith ${ }^{10}$ reviews the evidence regarding the quality of professional services from private pharmacies in low- and middle-income countries. The review suggests that the evidence-base is limited, but indicates that standards of service and care are often sub-optimal. If pharmacists in developing countries are to contribute effectively to health care, and ultimately patient outcomes, the barriers to providing higher quality care need to be investigated. Further, the ways in which these barriers might be overcome must be thought about and implemented sooner rather than later. ${ }^{10}$

Identified barriers include: a) recognition of the role and skill sets of pharmacists working within the wider health system as well as health care team; b) pharmacies to be led and managed only by graduate pharmacists; and c) provision of social security; that is a policy around national health insurance provision in developing countries.

Overcoming these barriers will provide a foundation for pharmacist-led services that target patients who will benefit from interventions that improve clinical outcomes. Chronic disease management, such as combating high glucose levels among diabetic patients, and the management of blood pressure and cholesterol levels is expected to improve the quality of life of these patients. Additionally, pharmacist-led services have been shown to reduce health service utilization, including visits to general practitioners. ${ }^{11}$

It is paramount to understand that low- and middleincome countries cannot be clustered together in terms of health systems and pharmacy service provision. They are not a homogeneous group of nations and subtle nuances as well as significant differences exist between these countries with regards to pharmacy practice. Further, the quality of service provision does not necessarily relate to the level of development of these countries, as reflected by their GDP. Taking Qatar as an example, it is a developing nation with a high relative GDP, and yet community pharmacies in that country have been reported to demonstrate questionable quality in terms of prescribing, labeling, dispensing, and counseling practices. ${ }^{12}$ These practices have been shown to be inconsistent with current guidelines, highlighting the need to implement professional development training programs to meet the obligations stated in the Qatar National Health Strategy 2011-2016. ${ }^{12}$

\section{Education, training, and professional factors}

Another important barrier to optimal service provision which compound on those presented by the health system and the level of service provision possible, is the pharmacists' themselves. Pharmacists' education and professional training could improve health system and quality of pharmacy services greatly in developing countries. Countries which have developed their pharmacy practices have invested huge resources in the area of pharmacists' education and training. Examples of these countries are: Taiwan, South Korea, Malaysia, Singapore, and Saudi Arabia. 
In low- and middle-income countries, it is speculated that the number of trained and competent pharmacists may be either unavailable or inadequately distributed to meet population needs. ${ }^{4} \mathrm{~A}$ bibliometric review on pharmacy education in low-to-middle income countries identified gaps in empirical research on pharmacy education and practice, especially in Central and South America, Africa, and Eastern Europe. ${ }^{13}$

\section{Concluding remarks}

This article sets out explore the barriers to effective practice in low- and middle-income countries. The literature in the context of both low- and high-income countries provides a sense of what these barriers might be, although this area remains relatively unexplored. What emerged are three main barriers at the macro, meso, and micro levels of health care. At the macro level the health systems per se may be hindering the further development of pharmacy services. At the meso level, the services that pharmacists are in a position to provide can be seen as both a facilitator and a barrier to effective pharmacy practice. Finally, at the micro level, the pharmacist themselves, the training they have, the way they think and act, and the way that others in the health care team perceive them has direct relevance and warrants further work in the developing world.

\section{Disclosure}

The authors report no conflicts of interest in this work.

\section{References}

1. FIP. News from the Federation. International Pharmaceutical Federation. 2005;19(2).

2. Babar ZU. Pakistan's National University of Pharmaceutical Sciences. Am J Pharm Edu. 2006;70(5):123.

3. Babar ZU, Vaughan C, Scahill S. Pharmacy practice: is the gap between the North and South widening? South Med Rev. 2012;5(1):1-2.

4. FIP. 2020 Vision: FIPS'S Vision, Mission and Strategic Plan. Available from: http://www.fip.org/files/fip/strategic\%20plan\%20no\%20annexes. pdf. Accessed February 18, 2014.

5. Haines A, Kuruvilla S, Borchert M. Bridging the implementation gap between knowledge and action for health. Bull World Health Organ. 2004;82:724-732.

6. Nuland SB. The doctors' plague: germs, childbed fever, and the strange story of Ignac Semmelweis. New York: WW Norton; 2003.

7. Parson A. Stem cell research awaits shifting tide. Boston Globe. August 2, 2004. Available from: http://www.boston.com/news/globe/ editorial_opinion/oped/articles/2004/08/02/stem_cell_research_awaits_ shifting_tide/. Accessed February 18, 2014.

8. International Food Policy Research Institute. Honduras family allowances program: monitoring and evaluation system. Washington, DC: International Food Policy Research Institute; 2000.

9. Gertler P. Final report: the impact of PROGRESA on health. Washington, DC: International Food Policy Research Institute; 2000.

10. Smith F. The quality of private pharmacy services in low and middle-income countries: a systematic review. Pharm World Sci. 2009;31(3):351-361.

11. Pande S, Hiller JE, Nkansah N, Bero L. The effect of pharmacistprovided non-dispensing services on patient outcomes, health service utilisation and costs in low- and middle-income countries. Cochrane Database Syst Rev. 2013;2:CD010398.

12. Ibrahim MI, Al-Sulaiti FK, Elshami SS. Do community pharmacists in Qatar practice rationally for a minor ailment? J Pharm Pract Res. 2013;43(1):79.

13. Babar ZU, Scahill SL, Akhlaq A, Garg S. A bibliometric review of pharmacy education literature in low and middle income countries. Curr Pharm Teach Learn. 2013;5(3):218-232.

\section{Publish your work in this journal}

Integrated Pharmacy Research and Practice is an international, peer-reviewed, open access, online journal, publishing original research, reports, reviews and commentaries on all areas of academic and professional pharmacy practice. This journal aims to represent the academic output of pharmacists and pharmacy practice with particular focus on integrated care. All papers are carefully peer reviewed

Submit your manuscript here: http://www.dovepress.com/integrated-pharmacy-research-and-practice-journal

to ensure the highest standards as well as ensuring that we are informing and stimulating pharmaceutical professionals. The manuscript management system is completely online and includes a very quick and fair peer-review system, which is all easy to use. Visit http://www.dovepress.com/testimonials.php to read real quotes from published authors. 